\title{
Hypertensive effect of calcilytic NPS 2143 administration in rats
}

\author{
Apolonia Rybczynska, Artur Lehmann, Anna Jurska-Jasko, Konrad Boblewski, Czeslawa Orlewska', \\ Henryk Foks ${ }^{1}$ and Krystyna Drewnowska ${ }^{2}$
}

Laboratory of Pathophysiology, ${ }^{1}$ Department of Organic Chemistry, Medical University of Gdansk, ul. Tuwima 15, 80-210 Gdansk, Poland

${ }^{2}$ Bostwick Laboratories, 4355 Innslake Drive, Glen Allen, VA 23060, USA

(Requests for offprints should be addressed to A Rybczynska; Email: aryb@amg.gda.pl)

\begin{abstract}
Secretion of parathormone (PTH), the main parathyroid hormone, which is under the control of the calcium sensing receptor, might be inhibited by calcimimetics and stimulated by calcilytics. Parathyroid glands also secrete parathyroid hypertensive factor. Recently, it was shown that calcimimetic NPS R-568 induced decreased blood pressure in spontaneously hypertensive rats (SHR) in the presence of parathyroid glands. Therefore, the aim of this study was to determine whether administration of the calcilytic NPS 2143 provoked an increase of mean arterial blood pressure (MAP) in normotensive rats. We used male Wistar rats anaesthetized with thiopental. Clearance experiments were performed and the effect of bolus, $1 \mathrm{mg} / \mathrm{kg}$ body weight i.v. of NPS 2143 on MAP in the presence and absence of thyroparathyroidectomy (TPTX) was monitored
\end{abstract}

continuously. Calcilytic properties of NPS 2143 were confirmed directly by a significant $(P<0 \cdot 05)$ increase of plasma $\mathrm{PTH}$ concentration, and indirectly by a rise of plasma $\mathrm{Ca}^{2+}$ concentration and urinary fractional phosphate excretion (FE Pi). NPS 2143 administration markedly $(P<0 \cdot 05)$ increased MAP, calculated as the difference $(\Delta)$ in MAP between sequential measurements and the time of bolus injection of calcilytic. The observed increase of blood pressure in the NPS 2143 group was also significant $(P<0 \cdot 05)$ compared with the control group. Performance of TPTX prevented the hypertensive effect of NPS 2143. We conclude that NPS 2143 is responsible for increased blood pressure in rats in the presence of parathyroid glands.

Journal of Endocrinology (2006) 191, 189-195

\section{Introduction}

The calcium receptor $(\mathrm{CaR})$, located at the surface of parathyroid cells, is sensitive to changes in plasma $\mathrm{Ca}^{2+}$ concentration, and plays a key role in the regulation of parathyroid hormone (PTH) secretion (Brown 1991, Brown \& MacLeod 2001). Activation of $\mathrm{CaR}$ by increased concentration of extracellular $\mathrm{Ca}^{2+}$ inhibits PTH secretion, and, in reverse, decrease of extracellular $\mathrm{Ca}^{2+}$ raises the PTH secretion by parathyroid cells. Therefore, the discovery of other compounds, in addition to $\mathrm{Ca}^{2+}$, that are able to influence $\mathrm{CaR}$, created the possibility to modulate parathyroid secretion. Development of compounds, called calcimimetics, that activate $\mathrm{CaR}$, enabled the suppression of PTH secretion in rats and humans (Steffey et al. 1993, Fox et al. 1999, Goodman et al. 2000). Calcimimetic compounds have great potential as an innovative medical approach to manage primary hyperparathyroidism (Silverberg et al. 1997) and secondary hyperparathyroidism in uraemia (Fox et al. 1999, Goodman et al. 2000). Moreover, recently synthesized calcilytics possessed properties that inhibit the activity of $\mathrm{CaR}$ and thus stimulate PTH secretion (Gowen et al. 2000, Nemeth et al. 2001). Therefore, calcilytic compounds might potentially be useful as anabolic therapy in osteoporotic patients.
We have recently reported that pharmacological modulation of CaR by calcimimetic NPS R-568 is responsible for decreased blood pressure in hypertensive (SHR) rats with intact parathyroids (not thyroparathyroidectomy (TPTX)), indicating the close relationship between the activation of $\mathrm{CaR}$, the presence of parathyroid glands, and blood pressure (Rybczynska et al. 2005). Furthermore, the calcimimetic NPS R-568 caused the marked and sustained antihypertensive effect in uraemic rats (Odenwald et al. 2006). Therefore, it might be presumed that the inactivation of $\mathrm{CaR}$ by cacilytics leads to increased blood pressure in normotensive rats.

The aim of our study was to compare the effect of the calcilytic NPS 2143 on mean arterial blood pressure (MAP) in normotensive rats in the presence and absence of parathyroid glands.

\section{Materials and Methods}

\section{Clearance experiments}

Male Wistar rats, weighing 200-280 g, were purchased from the Animal House of the Polish Academy of Sciences, Warsaw, Poland. All experiments were approved by The Local Ethical Committee on Animal Experiments. The animals 
were fed a commercial rodent chow (Purine, Poland) and tap water, available ad libitum. Rats were anaesthetized by i.p. injection of thiopental at the dose $40 \mathrm{mg} / \mathrm{kg}$ body weight and maintained under anaesthesia by thiopental supplementation during the experiment. The animals were placed on a heated table, and body temperature was maintained between 36 and $37^{\circ} \mathrm{C}$. TPTX by heat cauterization in some groups, and tracheostomy in all experimental groups were performed. Catheters were inserted into the carotid artery for blood sampling and pressure monitoring, into a jugular vein for infusions, and into the bladder for urine collection. Blood pressure was constantly monitored. Glomerular filtration rate (GFR) was measured as $\left[{ }^{3} \mathrm{H}\right]$ inulin clearance.

After all surgical procedures, including TPTX, a 2-h recovery period was allowed to establish steady state. During the first hour of this period, rats were infused with $4 \%$ albumin in isotonic saline at the rate of $5.6 \mathrm{ml} / \mathrm{h}$. This infusion was then replaced by isotonic saline at the same rate. During the second hour, an i.v. bolus of $\left[{ }^{3} \mathrm{H}\right]$ inulin (Amersham), $3 \mu \mathrm{Ci} / 250 \mathrm{~g}$ body weight was given and the infusion of saline supplemented with $\left[{ }^{3} \mathrm{H}\right]$ inulin $(0 \cdot 02 \mu \mathrm{Ci}$ / min) was started and maintained until the end of experiment.

\section{Experimental groups}

Six groups of rats were studied according to the following protocols:

Group 1, NPS $(\boldsymbol{n}=\mathbf{1 0})$ After $30-\min \left[{ }^{3} \mathrm{H}\right]$ inulin infusion, NPS 2143 (NPS), dissolved in 15\% cyclodextrin (Sigma) at a dose of $1 \mathrm{mg} / \mathrm{kg}$ body weight through venous catheter, was administered as a $300 \mu \mathrm{l}$ bolus. The time of administration of NPS was designated as time 0. Blood samples were taken at the midpoint of $10 \mathrm{~min}$ urine collection: $5 \mathrm{~min}$ before, and at 30,60 and $90 \mathrm{~min}$ after, administration of the tested agent.

Group 2, Control $(\boldsymbol{n}=\mathbf{8})$ The procedure with the rats was similar to that in group 1 with the exception that only $15 \%$ cyclodextrin was administered i.v.

Group 3, TPTX/NPS $(n=7)$ and Group 4, TPTX/control $(n=6)$ Before tracheostomy, each rat was thyroparathyroidectomized. All other procedures were the same as in groups 1 and 2, assuming that group 3 corresponds to group 1, and group 4 corresponds to group 2 .

In order to measure the effect of NPS 2143 on plasma PTH concentration, two additional groups of rats were included:

Group 5, NPS $(\boldsymbol{n}=\mathbf{1 0})$ After a 2-h recovery period, the NPS 2143, as in group 1, was administered as a bolus. Blood samples $(1.5 \mathrm{ml})$ for assay of PTH concentration were taken 10 min before and at 15, 40 and 60 min after administration of NPS 2143. To prevent excessive blood loss, immediately after separation of plasma, the sediment of red cells was rinsed with saline and reinfused as the erythrocyte concentrate.

Group 6, Control $(\boldsymbol{n}=\mathbf{5})$ The procedure with the rats was similar to that in group 5, with the exception that only $15 \%$ cyclodextrin was administered i.v.

\section{Measurements and calculations}

Total radioactivities of blood and urine samples were counted on the Liquid Scintillation Counter Wallac 1409 (LKB, Sweden). Phosphate concentrations in plasma and urine were determined according to the adapted method of Fiske \& SubbaRow (1925). The plasma $\mathrm{pH}$ and ionized calcium $\left[\mathrm{Ca}^{2+}\right]$ concentration were measured using an AVL 988-4 $\mathrm{Ca}^{2+} / \mathrm{pH}$ analyser (AVL, Vienna, Austria). Plasma $\mathrm{PTH}$ concentration was determined with rPTH radioimmunoassay kit (Pennisula Laboratories, Inc., San Carlos, CA, USA). Values are presented as means \pm s.E.M. Comparisons were made using Student's $t$-test. Significance was designated as $P<0 \cdot 05$.

Arterial blood pressure was monitored directly and sampled continuously at $100 \mathrm{~Hz}$, as we described previously (Rybczynska et al. 2005), using Biopac Systems, Inc., Model MP 100 (Goleta, CA, USA). The results of blood pressure measurements were elaborated with the help of the ACQKnowledge (Goleta, CA, USA) measurement system that is selected, scaled and filtered to remove accidental signal disturbances. The recorded time domain transient data have been presented as graphs with the help of Matlab Code (MathWorks, Inc., Natic, MA, USA).

Statistical ANOVAs of MAP were performed for $\triangle \mathrm{MAP}$, calculated as the difference in MAP between sequential measurements and time 0 min of the experiment for each group, as we described previously (Rybczynska et al. 2005). This allowed for direct comparison of responses to treatment between groups when baselines differed. Data were analysed by ANOVA with repeated measures, using Statistica StatSoft software (StatSoft, Inc., Tulsa, OK, USA), after NPS 2143 or vehicle treatment and in the presence or absence of TPTX. When the effect was significant, post hoc comparisons were performed using Bonferroni and Duncan tests. A value of $P<0 \cdot 05$ was considered statistically significant.

\section{Synthesis of calcilytic NPS 2143}

NPS 2143 was synthesized via addition of $(R)$-[1-(2-cyano-3chlorophenoxy)]-2',3'-epoxypropane (DelMar et al. 2003) to 1,1-dimethyl-2-(2-naphthyl)ethylamine obtained from the modified Ritter reaction of the tertiary alcohol and chloroacetonitrile (Jirgensons et al. 2000). In this way, the prepared amine was converted into its hydrochloride by a standard procedure. Structure and purity $(>99 \%)$ of the product was confirmed by ${ }^{1} \mathrm{H}$ and ${ }^{13} \mathrm{C}$ NMR, and microanalysis (CHN). 
The synthesis of NPS 2143 was carried out at the Department of Organic Chemistry, Faculty of Pharmacy, Medical University of Gdansk, Poland.

\section{Results}

Effect of synthesized NPS 2143 on plasma $\mathrm{Ca}^{2+}$, urinary phosphate excretion and plasma PTH concentration

In the presence of parathyroid glands, NPS 2143 administration resulted in a significant increase of plasma $\mathrm{Ca}^{2+}$ concentration in comparison with the control group as well as with the value before NPS 2143 application (Table 1). In the control group, no changes of plasma $\mathrm{Ca}^{2+}$ concentration were observed during the entire experiment. NPS 2143 markedly elevated urinary phosphate excretion, calculated as $\mathrm{FE}_{\mathrm{Pi}}$, when compared with the control group and with the time before calcilytic application. However, in the control group, a slight tendency to increased $\mathrm{FE}_{\mathrm{Pi}}$ was observed. GFR in both control and NPS 2143 groups remained in the physiological range, although a small decrease during the experiment occurred in the control group. There were no changes in GFR in the NPS 2143 group, except for its small increase versus the control group $60 \mathrm{~min}$ after calcilytic application. Plasma PTH concentration was significantly increased in the NPS 2143-treated group except $40 \mathrm{~min}$ after NPS 2143 injection where significance was not reached. Instead, in the control group the PTH level was decreased. The observed decrease was significant $40 \mathrm{~min}$ after vehicle injection (Table 2).

The effect of NPS 2143 administration in the presence of TPTX is shown in Table 3. Removal of parathyroid glands resulted in a significant decrease in plasma $\mathrm{Ca}^{2+}$ concentration by approximately $12 \%$ in the initial period when compared with control (no TPTX) animals (Table 1). We observed a continued decrease in plasma $\mathrm{Ca}^{2+}$ concentration versus the control period during the experiment; however, significance was reached only in NPS 2143-treated rats (Table 3). Performance of TPTX almost completely abolished phosphaturia in control and NPS 2143 groups in comparison with non-thyroparathyroidectomized rats (Table 1). This effect was unchanged throughout the experiment and was not dependent on NPS 2143 administration. There were no significant differences in GFR between control and NPS 2143 groups.

\section{Blood pressure measurement}

The effects of NPS 2143 on MAP in rats are summarized in Fig. 1. NPS 2143 administration resulted in increased MAP in normotensive, Wistar rats in comparison with the control and TPTX groups. The hypertensive effect of NPS 2143 is more sharply expressed when calculated as $\triangle \mathrm{MAP}$, the difference in MAP between sequential measurements and time 0 (Fig. 1b). However, baseline values of MAP were stable and remained in the physiological range, and the differences occurred because of the individual disparities between animals. Therefore, the estimation of $\triangle \mathrm{MAP}$ allowed for direct comparison of the responses to treatment between groups with different baseline values that underlined the significance in growth of blood pressure in the NPS 2143 experimental group compared with control and TPTX rats. Instead, in the control group, a small decrease of MAP was observed. Performance of TPTX also induced a small decrease in blood pressure, not significantly different from the control animals. Administration of the calcilytic in TPTX-NPS 2143 animals did not affect blood pressure significantly in comparison with the TPTX-control group.

\section{Discussion}

The present study demonstrates that i.v. administration of calcilytic NPS 2143, an inhibitor of CaR, increases blood pressure in normotensive rats (Fig. 1). This effect was observed only in the presence of parathyroid glands in rats. Administration of the calcilytic after TPTX did not influence blood pressure. These results are complementary to our previous findings that activation of the CaR by the calcimimetic NPS R-568 generates decreased blood pressure in hypertensive rats with intact parathyroids (Rybczynska et al. 2005)

Table 1 Effect of NPS 2143 administration on plasma $\mathrm{Ca}^{2+}$ concentration and urinary phosphate excretion in rats. Data are presented as means \pm S.E.M.

\begin{tabular}{|c|c|c|c|c|c|c|}
\hline & \multicolumn{2}{|c|}{$\mathbf{C a}^{2+}(\mathrm{mmol} / \mathrm{l})$} & \multicolumn{2}{|l|}{ GFR (ml/min) } & \multicolumn{2}{|l|}{$\mathbf{F E}_{\mathbf{P i}}(\%)$} \\
\hline & $C(n=8)$ & NPS $(n=10)$ & $\mathrm{C}(n=8)$ & NPS $(n=10)$ & $\mathrm{C}(n=8)$ & NPS $(n=10)$ \\
\hline \multicolumn{7}{|c|}{ Time of experiment (min) } \\
\hline $\begin{array}{l}-5 \\
0\end{array}$ & $1 \cdot 21 \pm 0 \cdot 02$ & $1 \cdot 25 \pm 0 \cdot 02$ & $\begin{array}{l}2 \cdot 73 \pm 0 \cdot 11 \\
\text { NPS } 2143,1\end{array}$ & $\begin{array}{l}2 \cdot 84 \pm 0 \cdot 06 \\
\text { body weight }\end{array}$ & $14 \cdot 2 \pm 1 \cdot 8$ & $11 \cdot 1 \pm 1 \cdot 9$ \\
\hline 30 & $1 \cdot 22 \pm 0 \cdot 02$ & $1 \cdot 37 \pm 0 \cdot 02 *^{+}$ & $2 \cdot 51 \pm 0 \cdot 12$ & $2 \cdot 87 \pm 0 \cdot 17$ & $16 \cdot 5 \pm 2 \cdot 1$ & $28 \cdot 3 \pm 2 \cdot 1^{* \dagger}$ \\
\hline 60 & $1 \cdot 24 \pm 0 \cdot 02$ & $1 \cdot 38 \pm 0 \cdot 03^{\dagger}$ & $2 \cdot 27 \pm 0 \cdot 13 *$ & $2 \cdot 83 \pm 0 \cdot 19^{\dagger}$ & $16 \cdot 4 \pm 2 \cdot 1$ & $25 \cdot 7 \pm 1 \cdot 3^{*}$ \\
\hline 90 & $1 \cdot 25 \pm 0 \cdot 01$ & $1 \cdot 44 \pm 0 \cdot 03^{*+}$ & $2 \cdot 12 \pm 0 \cdot 11^{*}$ & $2 \cdot 32 \pm 0 \cdot 26$ & $15 \cdot 8 \pm 2 \cdot 9$ & $21 \cdot 5 \pm 1 \cdot 6^{*+}$ \\
\hline 120 & $1 \cdot 25 \pm 0 \cdot 02$ & $1 \cdot 42 \pm 0 \cdot 04^{* \dagger}$ & $2 \cdot 15 \pm 0 \cdot 19^{*}$ & $2 \cdot 17 \pm 0 \cdot 16^{*}$ & $12 \cdot 3 \pm 1 \cdot 9$ & $23 \cdot 4 \pm 3 \cdot 0^{* \dagger}$ \\
\hline
\end{tabular}

GFR, glomerular filtration rate; $\mathrm{FE}_{\mathrm{Pi}}$, fractional excretion of phosphate; $\mathrm{C}$, control group; NPS, NPS 2143 group. Comparisons were made using Student's $t$-test; $* P<0 \cdot 05$ versus -5 min experiment; ${ }^{\dagger} P<0 \cdot 05$ versus control. 
Table 2 Effect of NPS 2143 administration on PTH plasma concentration in rats. Data are presented as means \pm S.E.M.

\begin{tabular}{|c|c|c|}
\hline \multirow[b]{3}{*}{ Time of experiment (min) } & \multicolumn{2}{|l|}{ PTH $(p g / m l)$} \\
\hline & Control $(n=5)$ & NPS $2143(n=10)$ \\
\hline & & \\
\hline-5 & $19 \cdot 8 \pm 5 \cdot 2$ & $20 \cdot 7 \pm 4 \cdot 7$ \\
\hline 0 & NPS $2143,1 \mathrm{mg} / \mathrm{kg}$ body weight & \\
\hline 15 & $10 \cdot 0 \pm 2 \cdot 2$ & $32 \cdot 2 \pm 0 \cdot 3^{*}$ \\
\hline 40 & $7 \cdot 8 \pm 1 \cdot 9^{*}$ & $24 \cdot 1 \pm 2 \cdot 7^{\dagger}$ \\
\hline 60 & $10 \cdot 2 \pm 2 \cdot 5$ & $32 \cdot 1 \pm 3 \cdot 0^{*+}$ \\
\hline
\end{tabular}

Comparisons were made using Student's t-test; ${ }^{*} P<0.05$ versus -5 min experiment; ${ }^{+} P<0 \cdot 05$ versus control.

and indicate the close relationship between parathyroids, activity of $\mathrm{CaR}$, and blood pressure.

It is well established that CaR, belonging to the class III of G-protein-coupled receptors, plays a key role in the mechanism of PTH secretion by parathyroid glands (Brown 1991, Brown \& MacLeod 2001). CaR activated physiologically by $\mathrm{Ca}^{2+}$ or pharmacologically by calcimimetics, decreases PTH secretion by parathyroids (Steffey et al. 1993, Fox et al. 1999, Goodman et al. 2000). Instead, CaR antagonists, calcilytics, increase the PTH secretion (Gowen et al. 2000, Nemeth et al. 2001). NPS 2143 was the first reported calcilytic, which, orally applied, induced rapid increase of circulating PTH in ovariectomized rats to an extent that stimulated new bone formation (Gowen et al. 2000). A rapid increase in plasma PTH level was also documented after intravenously infused NPS 2143 in normal rats (Nemeth et al. 2001).

The calcilytic NPS 2143 applied in our experiment was synthesized in our laboratory; therefore, special attention was given to identify its calcilytic activity, i.e. ability to increase PTH secretion. First, we directly demonstrated the significant increase of plasma PTH concentration after NPS 2143 administration compared with control rats. However, temporary debasement of PTH level was observed in both control and experimental groups; in the light of decreased PTH levels in the control group, the increase of PTH in NPS 2143 rats is evident. Secondly, we considered the significant increase of plasma $\mathrm{Ca}^{2+}$ concentration and fractional phosphate excretion as the supplemental and indirect confirmation of increased PTH secretion after NPS 2143 administration. These findings are consistent with other studies on normal (Nemeth et al. 2001) and osteopenic (Gowen et al. 2000) rats treated with NPS 2143 and documented that the synthesized NPS 2143 engenders calcilytical properties in our experimental conditions. Additionally, in the absence of PTH, after performance of TPTX, decreased plasma $\mathrm{Ca}^{2+}$ concentration and almost complete lack of phosphaturia were observed in rats. Moreover, TPTX procedure prevented the NPS 2143 effect to increase plasma $\mathrm{Ca}^{2+}$ and phosphate excretion in rats, indicating that the presence of parathyroids is necessary to demonstrate the calcilytic properties of NPS 2143.

However, several investigations using NPS 2143 (Gowen et al. 2000, Nemeth et al. 2001) and other calcilytic compounds (Arey et al. 2005) have been performed, and changes in blood pressure were not reported in these experiments. Therefore, the hypertensive effect of calcilytic NPS 2143 administration in this study is a new observation. Our data clearly show the significant rise of blood pressure after NPS 2143 injection compared with control animals. The observed slow decrease of blood pressure in control and TPTX animals was a consequence of the duration of the experiment, the surgical procedures and blood sampling in all rats. Therefore, the increase of blood pressure after NPS 2143

Table 3 Effect of NPS 2143 administration on plasma $\mathrm{Ca}^{2+}$ concentration and urinary phosphate excretion in TPTX rats. Data are presented as means \pm S.E.M.

\begin{tabular}{|c|c|c|c|c|c|c|}
\hline & \multicolumn{2}{|c|}{$\mathbf{C a}^{2+}(\mathrm{mmol} / \mathrm{l})$} & \multicolumn{2}{|c|}{ GFR (ml/min) } & \multicolumn{2}{|l|}{$\mathbf{F E}_{\mathrm{Pi}}(\%)$} \\
\hline & $C(n=6)$ & NPS $(n=7)$ & $\mathrm{C}(n=6)$ & NPS $(n=7)$ & $C(n=6)$ & NPS $(n=7)$ \\
\hline \multicolumn{7}{|c|}{ Time of experiment (min) } \\
\hline $0^{-5}$ & $1 \cdot 10 \pm 0 \cdot 08$ & $1 \cdot 10 \pm 0 \cdot 02$ & $\begin{array}{l}2 \cdot 70 \pm 0 \cdot 20 \\
\text { NPS } 2143,1\end{array}$ & $\begin{array}{l}2 \cdot 69 \pm 0 \cdot 11 \\
\text { body weight }\end{array}$ & $0 \cdot 46 \pm 0 \cdot 20$ & $0 \cdot 37 \pm 0 \cdot 07$ \\
\hline 30 & $1 \cdot 10 \pm 0 \cdot 06$ & $1 \cdot 04 \pm 0 \cdot 02$ & $2 \cdot 73 \pm 0 \cdot 20$ & $2 \cdot 49 \pm 0 \cdot 12$ & $0 \cdot 61 \pm 0 \cdot 20$ & $0 \cdot 32 \pm 0 \cdot 10$ \\
\hline 60 & $1 \cdot 00 \pm 0 \cdot 06$ & $1 \cdot 03 \pm 0 \cdot 02 *$ & $2 \cdot 67 \pm 0 \cdot 40$ & $2 \cdot 48 \pm 0 \cdot 17$ & $0 \cdot 75 \pm 0 \cdot 50$ & $0 \cdot 33 \pm 0 \cdot 10$ \\
\hline 90 & $1 \cdot 00 \pm 0 \cdot 07$ & $1 \cdot 01 \pm 0 \cdot 02 *$ & $2 \cdot 52 \pm 0 \cdot 20$ & $2 \cdot 68 \pm 0 \cdot 18$ & $0.56 \pm 0.56$ & $0 \cdot 30 \pm 0 \cdot 10$ \\
\hline 120 & $1 \cdot 00 \pm 0 \cdot 05$ & $0.97 \pm 0.03 *$ & $2 \cdot 70 \pm 0 \cdot 10$ & $2 \cdot 72 \pm 0 \cdot 17$ & $1 \cdot 05 \pm 0 \cdot 60$ & $0 \cdot 29 \pm 0 \cdot 10$ \\
\hline
\end{tabular}

TPTX, thyroparathyroidectomy; GFR, glomerular filtration rate; FE $_{\mathrm{Pi}}$, fractional excretion of phosphate; C, control group; NPS, NPS 2143 group. Comparisons were made using Student's $t$-test; ${ }^{*} P<0.05$ versus -5 min experiment. 
(a)

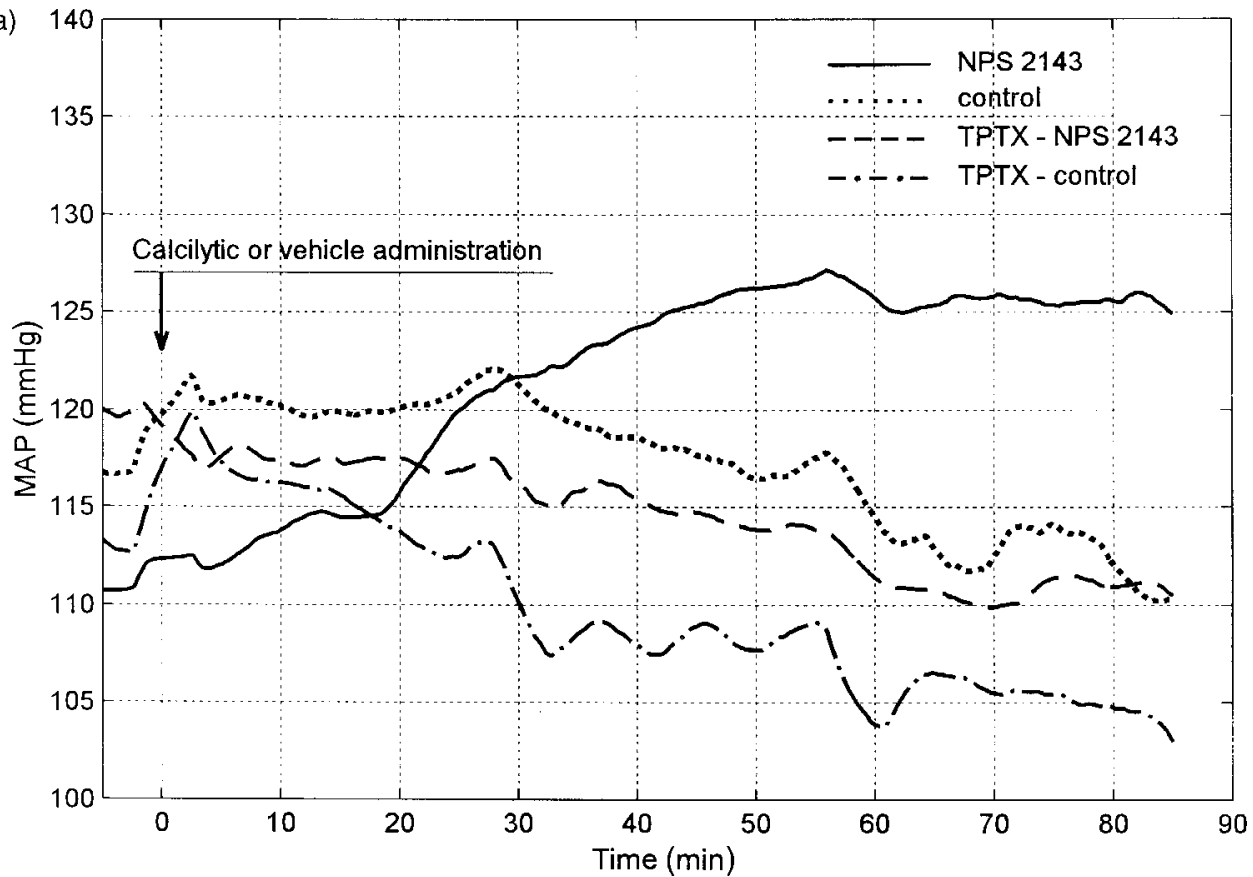

(b)

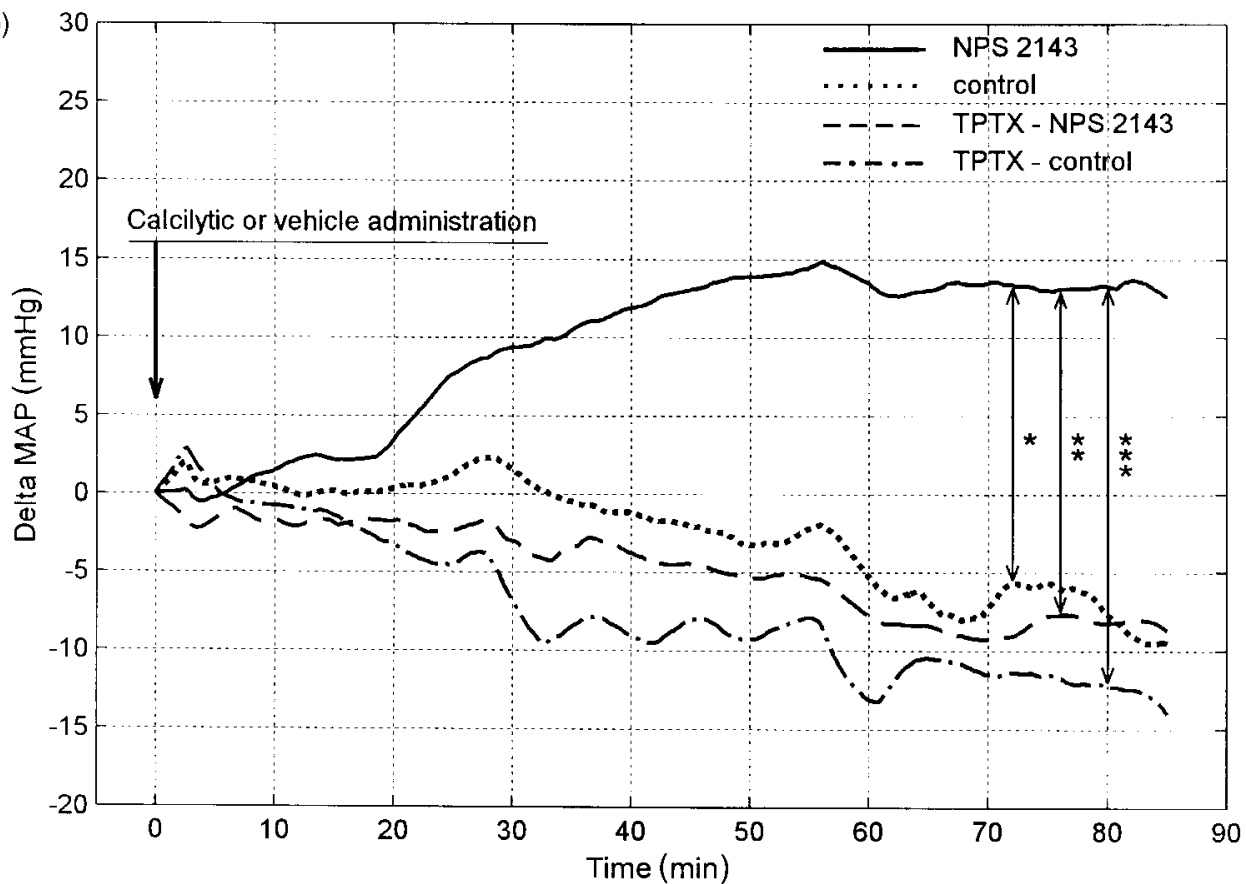

Figure 1 Effect of NPS 2143 or vehicle (control) administration (a) on MAP and (b) on $\triangle$ MAP (calculated as the difference of MAP between sequential measurement and time 0 min of experiment) in rats in the presence and absence of TPTX. Each point represents mean value of MAP or $\triangle$ MAP from: $n=10$ (NPS 2143), $n=8$ (control), $n=7$ (TPTX-NPS 2143), $n=6$ (TPTX-control) experiments. Comparisons were made using ANOVA with repeated measures, Bonferoni and Duncan tests; significance $P<0 \cdot 05$, was found for comparisons: *NPS 2143 versus control; **NPS 2143 versus TPTX-NPS 2143; ***NPS 2143 versus TPTX-control. 
administration in comparison with the decrease in the control and TPTX groups underlined the hypertensive effect of the calcilytic. To investigate whether this effect was specifically dependent on the impact of the calcilytic on parathyroid glands, we monitored blood pressure in thyroparathyroidectomized rats. The blood pressure in the TPTX groups was not statistically different from that observed in control animals. Moreover, performance of TPTX procedure induced insensitivity of blood pressure to NPS 2143 administration in rats. These observations suggest that the presence of parathyroids is the necessary condition to induce hypertension after calcilytic administration in rats.

It is possible that $\mathrm{CaR}$, through mechanisms similar to those that control PTH secretion, might mediate the secretion of other substances produced by the parathyroid glands. It is well documented that parathyroid glands secrete parathyroid hypertensive factor (PHF), which is confirmed in SHR (Lewanczuk et al. 1989, Lewanczuk \& Pang 1990, Schluter et al. 1993, Benishin et al. 1994) and also in patients with primary hyperparathyroidism and hypertension (Schulter et al. 1992, Lewanczuk et al. 1994). To date, the structure of PHF is not known. There was the proposition that the structure of PHF has a peptide moiety and a lysosomal moiety that both are critical for the biological activity (Benishin et al. 1994). The molecular mass of this factor was estimated to be in the range $2 \cdot 5-3 \cdot 0 \mathrm{kDa}$ (Benishin et al. 1991). Recently, an enzyme immunoassay for detection of PHF in human plasma has been reported (Krylova et al. 2003).

It was observed that surgically removing hyperactive parathyroids induced decreased blood pressure in SHR (Mann et al. 1987, Onsgaard-Meyer et al. 1994, Rybczynska et al. 2005) as well as in patients with primary hyperparathyroidism (Diamond et al. 1986, Resnik et al. 1986, Niederle et al. 1987). These findings indicated the connection between parathyroid glands and observed hypertension. Moreover, it was documented recently that pharmacological parathyroidectomy, realized by calcimimetic NPS R-568 administration, resulted in decreased blood pressure in SHR with intact parathyroids (Rybczynska et al. 2005). This observation suggests that $\mathrm{CaR}$ present on the surface of parathyroid cells may have mediated the mechanisms that influence blood pressure. The possibility should be considered that the hypotensive effect of calcimimetic NPS R-568 in SHR and the hypertensive effect of calcilytic NPS 2143 in normotensive rats are the effects of decreased and increased PHF secretion respectively. This hypothesis is strengthened by the study suggesting the involvement of $\mathrm{CaR}$ in the regulation of PHF secretion, indicating an increased PHF secretion by cultured SHR cells in low $\mathrm{Ca}^{2+}$ medium (Sutherland \& Benishin 2004).

Several investigators have reported that the $\mathrm{CaR}$ is expressed in many cardiovascular tissues, including human aortic endothelial cells (Ziegelstein et al. 2006), rat cardiomyocytes (Tfelt-Hansen et al. 2006) and is also present in rat s.c. small arteries (Ohanian et al. 2005). Therefore, the influence of calcilytic on blood pressure is not excluded.
However, in our experimental conditions, such a possibility seems to be unlikely since the blood pressure measurements in control and in TPTX-NPS 2143 treated rats were not statistically different.

Administration of calcilytic NPS 2143 in our study increased the plasma PTH concentration in rats (Table 2). The known effect of the single doses of 1-34 PTH (Pang et al. 1980, Saglikes et al. 1985, Baksi 1988) or 1-84 PTH (Saglikes et al. 1985) is the activity that transiently decreases blood pressure in intact (Pang et al. 1980, Saglikes et al. 1985) or thyroparathyroidectomized (Baksi 1988) animals. In these experiments, the decrease in blood pressure was observed immediately, within about $1 \mathrm{~min}$, after PTH injection. Moreover, when, after bolus injection, continuous infusion of 1-34 PTH was applied, no changes of blood pressure during the further duration of the experiments on TPTX rats were observed (Rybczynska et al. 1990). In our study, increased blood pressure after application of NPS 2143 was observed. Therefore, the possible influence of increased plasma PTH concentration in our study should be taken into consideration as the element that, if anything, might decrease blood pressure in rats. Consequently, the time course of the observed blood pressure changes in rats treated with NPS 2143 might reflect the final effect of secretion by the parathyroids of both PTH and the hypertensive substance, most likely PHF.

In summary, the present study demonstrates that administration of the calcilytic NPS 2143 increases blood pressure in normotensive rats only in the presence of parathyroid glands.

\section{Funding}

The study was supported by the Polish Committee for Scientific Research, grant 2 P05A 06427 and the Medical University of Gdansk, grant ST-54. The authors declare that they have no conflict of interest that would preclude their impartiality in this work.

\section{References}

Arey BJ, Seethala R, Ma Z, Fura A, Morin J, Swartz JA, Vyas V, Yang W, Dicson JK Jr \& Feyen JHM 2005 A novel calcium sensing receptor antagonist transiently stimulates parathyroid hormone secretion in vivo. Endocrinology 146 2015-2022.

Baksi SN 1988 Hypotensive action of parathyroid hormone in hypoparathyroid and hyperparathyroid rats. Hypertension 11 509-513.

Benishin CG, Lewanczuk RZ \& Pang PKT 1991 Purification of parathyroid hypertensive factor from plasma of spontaneously hypertensive rats. PNAS 88 6372-6376.

Benishin CG, Lewanczuk RZ, Shan J \& Pang PKT 1994 Pang purification and structural characterization of parathyroid hypertensive factor. Journal of Cardiovascular Pharmacology 23 S9-S13.

Brown EM 1991 Extracellular $\mathrm{Ca}^{2+}$ sensing, regulation of parathyroid cell function, and role of $\mathrm{Ca}^{2+}$ and other ions as extracellular (first) messengers. Physiological Review 71 371-411.

Brown EM \& MacLeod RJ 2001 Extracellular calcium sensing and extracellular calcium signaling. Physiological Reviews 81 239-297. 
DelMar EG, Barmore RM, Sheehan D, Van Wagen BC, Callahan JF, Keenan RM, Kotecha NR, Lago AM, Southall LS \& Thomson M 2003 Calcilytic compounds. United States Patent 6521667.

Diamond TW, Botha JR, Wing J, Meyers AM \& Kalk WJ 1986 Parathyroid hypertension - a reversible disorder. Archives of Internal Medicine 146 1709-1712.

Fiske CH \& SubbaRow Y 1925 The colorimetric determination of phosphorus. Journal of Biological Chemistry 66 375-400.

Fox J, Lowe SH, Conklin RL \& Nemeth EF 1999 The calcimimetic NPS R-568 decreases plasma PTH in rats with mild and severe renal or dietary secondary hyperparathyroidism. Endocrine 10 97-103.

Goodman WG, Frazao JM, Goodkin DA, Turner SA, Liu W \& Coburn JW 2000 A calcimimetic agent lowers plasma parathyroid hormone levels in patients with secondary hyperparathyroidism. Kidney International 58 436-445.

Gowen M, Stroup GB, Dodds RA, James IE, Votta BJ, Smith BR, Bhatnagar PK, Lago AM, Callhan JF, DelMar EG et al. 2000 Antaginizing the parathyroid calcium receptor stimulates parathyroid hormone secretion and bone formation in osteopenic rats. Journal of Clinical Investigation 105 1595-1604.

Jirgensons A, Kauss V, Kalvinsh I \& Gold MR 2000 A practical synthesis of tert-alkyloamines via the Ritter reaction with chloroacetonitrile. Synthesis 1709-1712.

Krylova S, Labedz T, Lewanczuk RZ \& Benishin CG 2003 Generation, characterization, and use of monoclonal antibodies against parathyroid hypertensive factor. Clinical Chemistry 49 1204-1206.

Lewanczuk RZ \& Pang PKT 1990 Vascular and calcemic effects of plasma of spontaneously hypertensive rats. American Journal of Hypertension 3 189S-194S.

Lewanczuk RZ, Wang J, Zhang ZR \& Pang KT 1989 Effects of spontaneously hypertensive rat plasma on blood pressure and tail artery calcium uptake in normotensive rats. American Journal of Hypertension 2 26-31.

Lewanczuk RZ, Resnick LM, Ho MS, Benishin CG, Shan J \& Pang PKT 1994 Clinical aspects of parathyroid hypertensive factor. Journal of Hypertension 12 11-16.

Mann JFE, Wiecek A, Bommer J, Ganten U \& Ritz E 1987 Effects of parathyroidectomy on blood pressure in spontaneously hypertensive rats. Nephron 62 465-469.

Nemeth EF, DelMar EG, Heaton WL, Miller MA, Lambert LD, Conklin RL, Gowen M, Gleason JG, Bhatnagar PK \& Fox J 2001 Calcylitics compounds: potent and selective $\mathrm{Ca}^{2+}$ receptor antagonists that stimulate secretion of parathyroid hormone. Journal of Pharmacology and Experimental Therapeutics 299 323-331.

Niederle B, Roka R, Woloszczuk W, Klaushofer K, Kovarik J \& Schnernthaner G 1987 Successful parathyroidectomy in primary hyperparathyroidism: a clinical follow- up study in 212 consecutive patients. Surgery 102 903-909.

Odenwald T, Nakagawa K, Hadtstein Ch, Roesck F, Gohlke P, Ritz E, Schaefer F \& Schmidt CP 2006 Acute blood pressure effects and chronic hypotensive action of calcimimetic in uremic rats. Journal of the American Society of Nephrology 17 662-665.

Ohanian J, Gatfield KM, Ward DT \& Ohanian V 2005 Evidence for a functional calcium-sensing receptor that modulates myogenic tone in rat subcutaneous small arteries. American Journal of Physiology 288 H1756-H1762.
Onsgaard-Meyer MJ, Berndt TJ, Khraibi AA \& Knox FG 1994 Phosphaturic effect of parathyroid hormone in the spontaneously hypertensive rats. American Journal of Physiology 267 R78-R83.

Pang PKT, Tenner TE Jr, Yee JA \& Janssen HF 1980 Hypotensive action of parathyroid hormone preparations on rats and dogs. PNAS 77 675678.

Resnik LM, Muller FB \& Laragh JH 1986 Calcium-regulating hormones in essential hypertension. Annals of Internal Medicine 105 649-654.

Rybczynska A, Berndt TJ, Hoppe A \& Knox FG 1990 Site of restoration of the effect of PTH by propranolol in respiratory alkalosis. Kidney International 38 258-262.

Rybczynska A, Boblewski K, Lehmann A, Orlewska C, Foks H, Drewnowska K \& Hoppe A 2005 Calcimimetic NPS R-568 induces hypotensive effect in spontaneously hypertensive rats. American Journal of Hypertension 18 364-371.

Saglikes Y, Massry SG, Iseki K, Nadler JL \& Campese VM 1985 Effect of PTH on blood pressure and response to vasoconstrictor agonists. American Journal of Physiology 248 F674-F681.

Schulter H, Quante C, Buchholz B, Dietl KH, Spieker C, Karas M \& Zidek W 1992 A vasopressor factor partially purified from human parathyroid glands. Biochemical and Biophysical Research Communication 188 323-329.

Schluter H, Kluth B, Borjesson-Stoll R, Nordhoff E \& Zidek W 1993 Partial purification and characterization of a circulating hypertensive factor in spontaneously hypertensive rats. European Journal of Biochemistry 218 67-73.

Silverberg SJ, Bone HG III, Marriott TB, Locker FG, Thys-Jacobs S, Dziem G, Kaatz S, Sanguinetti EL \& Bilezikian JP 1997 Short-term inhibition of parathyroid hormone secretion by a calcium-receptor agonist in patients with primary hyperparathyroidism. New England Journal of Medicine 337 1506-1510.

Steffey ME, Fox J, Van Wagenen BC, Delmar EG, Balandrin MF \& Nemeth EF 1993 Calcimimetics: structurally and mechanistically novel compounds that inhibit hormone secretion from parathyroid cells. Journal of Bone and Mineral Research 8 S175.

Sutherland SK \& Benishin CG 2004 Regulation of parathyroid hypertensive factor secretion by $\mathrm{Ca}^{2+}$ in spontaneously hypertensive rat parathyroid cells. American Journal of Hypertension 17 266-272.

Tfelt-Hansen J, Hansen JL, Smajilovic S, Terwillinger EF, Haunso S \& Sheikh SP 2006 Calcium receptor is functionally expressed in rat neonatal ventricular cardiomyocytes. American Journal of Physiology 290 H1165-H1171.

Ziegelstein RC, Xiong Y, He C \& Hu Q 2006 Expression of a functional extracellular calcium-sensing receptor in human aortic endothelial cells. Biochemical and Biophysical Research Communication 342 153-163.

Received 18 April 2006

Received in final form 25 June 2006

Accepted 30 June 2006

Made available online as an Accepted Preprint 1 August 2006 